\title{
Microwave-assisted extraction optimization of Sabah snake grass (Clinacanthus nutans Lindau) herbal infusion and evaluation of antioxidant and acetylcholinesterase inhibition activity in vitro
}

\author{
Shafie, N.S.M., Latif, M.S. Ghazali, M.I., Abbas, S. and "Kormin, F. \\ Department of Technology and Natural Resources, Faculty of Applied Sciences and Technology, Universiti \\ Tun Hussein Onn Malaysia (UTHM), Pagoh Educational Hub, KM 1, Jalan Panchor, 84000, Muar, Johor, \\ Malaysia
}

\author{
Article history: \\ Received: 25 October 2019 \\ Received in revised form: 26 \\ February 2020 \\ Accepted: 28 February 2020 \\ Available Online: 4 June \\ 2020
}

Keywords:

Acetylcholinesterase

inhibition,

Clinacanthus nutans,

Microwave-assisted

extraction,

Optimization,

Response surface

methodology

DOI:

https://doi.org/10.26656/fr.2017.4(5).353

\begin{abstract}
Clinacanthus nutans is a great medicinal herb with high polyphenols content and had been used in its infusion form to treat illness. In this paper, microwave-assisted extraction of $C$. nutans tea infusion was investigated by using central composite design combined with response surface methodology. The influence factors of microwave power $(80-800 \mathrm{~W})$; brewing time duration $(0-240 \mathrm{~s})$ and extraction time duration $(60 \mathrm{~s}-300 \mathrm{~s})$ on total phenolic content (TPC), total flavonoid content (TFC), antioxidant activity (DPPH) and acetylcholinesterase inhibition activity $(\mathrm{AChE})$ were investigated. The optimum extraction conditions were determined as follows: microwave power $\mathrm{X}_{1}, 560 \mathrm{~W}$; brewing duration, $\mathrm{X}_{2}, 60 \mathrm{~s}$ and extraction time, $\mathrm{X}_{3}, 240 \mathrm{~s}$. Under this optimal extraction conditions, the responses were as followed: Total phenolic content $(251.58 \pm 10.98 \mathrm{mg} \mathrm{GAE} / \mathrm{L})$; Total flavonoid content $(102.21 \pm 5.16 \mathrm{mg} \mathrm{RE} / \mathrm{L})$; DPPH $(62.22 \pm 0.03 \%)$ and acetylcholinesterase inhibition activity (AChE) of $24.77 \pm 0.12 \%$. Results demonstrated that MAE could be used to extract bioactive constituents having antioxidant and anti-acetylcholinesterase properties that may benefit in Alzheimer's disease.
\end{abstract}

\section{Introduction}

Clinacanthus nutans (Burm f.) Lindau from the Acanthaceae family is a native species to tropical Southeast Asian countries, and commonly known as "Belalai gajah" or "Sabah snake grass" in Malaysia. In Malaysia and Singapore, the fresh leaves of $C$. nutans were traditionally used as an infusion and served in tea form and have great health benefits to the consumers. $C$. nutans have been used to treat skin rashes, insects and snake bites, (Sakdarat et al., 2009), mental stress, diabetes, rheumatoid arthritis, fever, dysentery, burns, scalds, diarrhea (Rahim et al., 2016), skincare, cancer prevention, cold and flu and even goitre (Siew et al., 2014). C. nutans extracts also were reported to exhibit antiviral activity against herpes simplex virus infection, varicella-zoster virus, derived from the family of Herpesviridae (Kongkaew and Chaiyakunapruk, 2011), antibacterial, anti-inflammatory, anticancer $(\mathrm{Ng}$ et al., 2017), antioxidant, antiproliferative and antinociceptive activity (Rahim et al., 2016). Apart from that, oral toxicity study suggested that $C$. nutans are safe for consumption in Dawley female rats (Lau et al., 2014). Hexane fraction of $C$. nutans leaves revealed compounds of stigmasterol, $\beta$-sitosterol and a triterpenoid lupeol (Le et al., 2017). The phytochemical compounds of terpenoids, flavonoids, C-glycosyl flavones, sulfurcontaining glucosides and glycogylcerolipids were identified in most of $C$. nutans plants research study. These phytochemical compounds were found to have pharmacological properties of antiviral, anticancer, antioxidant, antidiabetic, immunomodulatory, wound healing, anti-inflammatory and analgesic activities (Yahaya et al., 2015).

Acetylcholine $(\mathrm{ACh})$ is neurotransmitter located in the peripheral and central nervous system (CNS) that have a crucial role in memory, learning and behavioral activities. Reduction of $\mathrm{ACh}$ levels in the brain could lead to Alzheimer's disease (AD). One of the therapeutic approaches in treating $\mathrm{AD}$ via the inhibition of acetylcholinesterase $(\mathrm{AChE})$. The $\mathrm{AChE}$ role is to terminate the cholinergic neurotransmission by hydrolysis of ACh (Grisaru et al., 1999). The ACh restoration can be generated by using acetylcholinesterase inhibitors (AChEIs) that varies from natural (alkaloids, terpenoids, glycosides, coumarins), semisynthetic and synthetic derivatives. Tacrine, 
donepezil, rivastigmine and galanthamine are AChEIs that are approved by the US Food and Drug Administration and used to treat $\mathrm{AD}$ symptoms (Ouattara et al., 2013). Studies have shown that phytochemicals can be great AChEI with little or no side effect and could be used as dietary supplements (Neagu et al., 2015). Thus, free radical and antioxidant balanced production play a role in the prevention of $\mathrm{AD}$ and having $\mathrm{AChEI}$ that possessed antioxidant activities derived from the natural origin are a big concern.

Extraction techniques are one of the crucial analytical steps in determining extract compositions. Phenolic compounds are commonly extracted using conventional extraction such as simple maceration, infusion and decoction (Dai and Mumper, 2010). However, these conventional methods take up longer time and use a large amount of solvents. Thus, finding a convenient extraction method of shorter extraction time with lower solvent consumption with great yields is a great benefit. Microwave-assisted extraction (MAE) is a green technology that meets the requirements on finding a convenient extraction method compared to other extraction techniques (Mustapa, Martin, Galego et al., 2015; Krishnan and Rajan, 2016; Panja, 2018).

MAE use the microwave to enhance the heating process of the solvent-sample system with shorter extraction time and lower solvent volume compared to conventional extraction. Mechanisms involved in microwave heating are dipole rotation and ionic conduction (Faridah et al., 2018). Dipole rotation occurs as solvent and sample molecules having dipole moments align on electric field rotate and produce thermal energy (Veggi et al., 2013). The ionic conduction occurs in solvent containing ions when the electromagnetic field is applied, where heat is generated due to friction between ions flow and the solvent itself. A study showed that brewing green tea for $30 \mathrm{~s}$ in freshly boiled water before irradiation for $60 \mathrm{~s}$ in microwave oven improved extract yield of catechins and caffeine compared to used microwave oven alone (Vuong et al., 2012). Thus, brewing time outside the microwave oven is added in this study to assist in the microwave-assisted extraction.

Apart from one-factor-one-time approach (single factor experiment), response surface methodology (RSM) could also be used in the optimization process. RSM is a statistical technique to optimize and evaluate multiple factors effects and the influence on one or more response variables (Kormin et al., 2010; Simic et al., 2016; Caleja et al., 2017). In this project, we investigated the RSM technique of central composite design (CCD) to optimize microwave-assisted extraction infusion parameter such as microwave power, brewing time and extraction time to maximize the total phenolic content, total flavonoid content, DPPH antioxidant activity and AChE inhibition activity of $C$. nutans in its tea form.

\section{Materials and methods}

2.1 Chemicals

2,2-diphenyl-1-picrylhydrazl (DPPH); 5,5-dithio-bis(2-nitrobenzoic acid) DTNB; Rutin hydrate; galanthamine hydrobromide were purchased from Sigma -Aldrich, USA. acetylcholinesterase from electrophorus eel, aluminium chloride anhydrous; ascorbic acid; diSodium hydrogen phosphate di-hydrate; folin-ciocalteu; gallic acid; hydrochloric acid magnesium chloride hexahydrate; methanol; sodium dihydrogen phosphate monohydrate; sodium hydroxide pellet; sodium nitrite; sodium chloride and Tris-HCL were purchased from Merck, Germany. 2,4,6-Tris (2-pyridyl)-s-triazine (TPTZ) was purchased from Sigma, USA. All reagents used were of analytical grade.

\subsection{Sample preparation}

The herbal plant was obtained from a local supplier in Batu Pahat, Johor, Malaysia. The plant leaves were first cut and washed several times with running tap water to remove dirt. Next, the leaves were rinsed with distilled water to remove any impurities followed by drying in hot air oven (Memmert, Germany) for 2 days at $45^{\circ} \mathrm{C}$ (Abdullah et al., 2012). Then, the leaves were ground into a fine powder using an electric grinder. The plant powder obtained was stored in an airtight container at room temperature until further use.

\subsection{Microwave infusion preparation}

A commercial microwave oven (nns215mf, Panasonic, Japan, $800 \mathrm{~W}$ ) was used. A total of $2 \mathrm{~g}$ of dried leaves were infused with $200 \mathrm{~mL}$ boiling deionized water at $100^{\circ} \mathrm{C}$ under magnetic stirrer (brewing time) before placed in microwave oven under the following parameter as shown in Table 1 (microwave power, irradiate time). The infusion then was filtered with Whatman filter paper no 1 before used in the assay. The infusion was prepared freshly before the assay was carried out.

\subsection{Experimental design}

Response surface methodology (RSM) of central composite design for MAE of Clinacanthus nutans phytochemical content, antioxidant capacities and enzymatic activity was determined to optimize the process as in Table 1. Variables that were used in the MAE optimization were microwave power $(80-800$ $\mathrm{W})$; brewing time $(0-240 \mathrm{~s})$ and extraction time $(60-$ 300 s). A full factorial central composite design with 20 
Table 1. Experimental design layout and responses for Central Composite Design (CCD) based on response surface methodology (RSM) of $C$. nutans infusions phytochemical content, antioxidant activities and enzymatic activity using microwave assisted extraction (MAE) (in triplicate).

\begin{tabular}{cccccccc}
\hline Run & $\mathrm{A}$ & $\mathrm{B}$ & $\mathrm{C}$ & $\mathrm{Y}_{1}$ & $\mathrm{Y}_{2}$ & $\mathrm{Y}_{3}$ & $\mathrm{Y}_{4}$ \\
\hline 8 & 560 & 180 & 240 & $301.35 \pm 2.09$ & $117.67 \pm 4.58$ & $65.43 \pm 0.74$ & $28.27 \pm 2.51$ \\
3 & 240 & 180 & 120 & $250.21 \pm 2.37$ & $93.42 \pm 3.78$ & $72.84 \pm 0.45$ & $24.25 \pm 0.26$ \\
13 & 440 & 120 & 60 & $239.25 \pm 5.97$ & $87.67 \pm 10.65$ & $69.56 \pm 0.39$ & $21.76 \pm 0.67$ \\
7 & 240 & 180 & 240 & $247.47 \pm 6.85$ & $84.64 \pm 3.28$ & $70.73 \pm 0.63$ & $20.13 \pm 1.68$ \\
6 & 560 & 60 & 240 & $322.81 \pm 15.8$ & $124.33 \pm 10.14$ & $63.85 \pm 0.88$ & $28.28 \pm 0.44$ \\
18 & 440 & 120 & 180 & $250.66 \pm 0.79$ & $105.24 \pm 3.78$ & $62.59 \pm 1.03$ & $26.99 \pm 0.36$ \\
10 & 800 & 120 & 180 & $338.33 \pm 39.92$ & $133.12 \pm 7.35$ & $60.64 \pm 0.82$ & $31.12 \pm 2.01$ \\
1 & 240 & 60 & 120 & $247.01 \pm 17.13$ & $99.18 \pm 1.57$ & $71.22 \pm 0.45$ & $23.68 \pm 1.47$ \\
2 & 560 & 60 & 120 & $263.9 \pm 11.86$ & $116.15 \pm 6.05$ & $65.04 \pm 0.68$ & $27.42 \pm 0.71$ \\
20 & 440 & 120 & 180 & $250.21 \pm 6.28$ & $106.45 \pm 4.17$ & $62.72 \pm 1.03$ & $26.46 \pm 0.23$ \\
15 & 440 & 120 & 180 & $247.47 \pm 15.44$ & $93.42 \pm 10.14$ & $68.37 \pm 0.93$ & $21.20 \pm 0.95$ \\
11 & 440 & 0 & 180 & $283.54 \pm 17.4$ & $74.64 \pm 1.39$ & $71.62 \pm 3.08$ & $18.99 \pm 0.69$ \\
12 & 440 & 240 & 180 & $273.95 \pm 10.37$ & $91.61 \pm 2.62$ & $69.08 \pm 0.31$ & $22.58 \pm 1.26$ \\
4 & 560 & 180 & 120 & $250.66 \pm 9.12$ & $109.18 \pm 2.73$ & $66.30 \pm 1.13$ & $22.52 \pm 0.48$ \\
14 & 440 & 120 & 300 & $289.02 \pm 10.1$ & $118.88 \pm 3.44$ & $65.29 \pm 1.45$ & $26.66 \pm 0.92$ \\
5 & 240 & 60 & 240 & $248.38 \pm 11.16$ & $93.73 \pm 5.96$ & $71.44 \pm 1.01$ & $20.14 \pm 1.14$ \\
19 & 440 & 120 & 180 & $260.25 \pm 4.81$ & $96.15 \pm 8.20$ & $65.05 \pm 1.27$ & $26.90 \pm 0.21$ \\
16 & 440 & 120 & 180 & $256.14 \pm 5.54$ & $106.45 \pm 3.28$ & $63.54 \pm 0.30$ & $25.74 \pm 0.14$ \\
9 & 80 & 120 & 180 & $259.79 \pm 14.5$ & $81.91 \pm 1.82$ & $71.75 \pm 0.73$ & $21.70 \pm 0.76$ \\
17 & 440 & 120 & 180 & $257.51 \pm 3.45$ & $99.18 \pm 7.10$ & $64.50 \pm 0.27$ & $30.16 \pm 3.67$ \\
\hline B & & & $\mathrm{C}$ & &
\end{tabular}

$\mathrm{A}=$ Power $(\mathrm{W}) ; \mathrm{B}=$ Brewing time (s); $\mathrm{C}=$ Irradiate time (s); $\mathrm{Y}_{1}=$ Total phenolic content (TPC; mg GAE/L); $\mathrm{Y}_{2}=$ Total flavonoid content (TFC, mg RE/L); $\mathrm{Y}_{3}=\mathrm{DPPH}$ (\% Inhibition); $\mathrm{Y}_{4}=\mathrm{AChE}$ (\% Inhibition).

experiments run was completed. The experiments were done according to the run numbers as arranged by the software to avoid errors. Responses of the experimental design were phytochemical content (Total phenolic content; Total flavonoid content), antioxidant activities (DPPH, FRAP, ABTS) and enzymatic activity (AChE inhibition activity). The obtained data of the responses were analyzed by using multiple regressions to fit the sond-order polynomial model.

$Y=\beta_{0}+\sum \beta_{i} x_{i}+\sum \beta_{i i} x_{i}^{2}+\sum \beta_{i j} x_{i} x_{j} \mathrm{Y}=\beta_{0}+\sum \beta_{i} \mathrm{x}_{\mathrm{i}}+\sum \beta_{\mathrm{ii}} \mathrm{x}_{\mathrm{i}}^{2}+\sum \beta_{\mathrm{ij}} \mathrm{x}_{\mathrm{i}} \mathrm{x}_{\mathrm{j}}$ (1)

Where $Y=$ response function; $\beta_{0}=$ regression coefficient for intercept; $\beta_{\mathrm{i}}=$ regression coefficient for linear; $\beta_{\mathrm{ii}}=$ regression coefficient for quadratic; $\beta_{\mathrm{ij}}=$ regression coefficient for interaction; and $\chi_{\mathrm{i}}$ and $\chi_{\mathrm{j}}=$ independent variables

\subsection{Total phenolic content determination (TPC)}

Determination of TPC assay used Folin - Ciocalteu colorimetric method (Maisarah et al., 2013). $200 \mu \mathrm{L}$ herbs infusion was mixed with $1.5 \mathrm{~mL}$ of FolinCiocalteu's reagent (10 folds), left for 5 mins before 1.5 $\mathrm{mL}$ of $6 \%(\mathrm{w} / \mathrm{v})$ sodium bicarbonate solution was added and left for another 90 mins and measured at $725 \mathrm{~nm}$ by using a spectrophotometer. The polyphenols concentration was calculated by using gallic acid as a standard reference with a concentration between 0 to 120 $\mu \mathrm{g} / \mathrm{mL}$. The sample was analyzed in triplicates and expressed as milligram gallic acid equivalents per liter ( $\mathrm{mg} \mathrm{GAE} / \mathrm{L}$ ). The standard equation curve of gallic acid was $y=0.0073 x+0.0635,\left(R^{2}=0.9985\right)$.

\subsection{Total flavonoid content determination}

This assay was determined by aluminium chloride colorimetric method (Lusia et al., 2015). Sample infusion $(1 \mathrm{~mL})$ was mixed with $4 \mathrm{~mL}$ deionized water, $5 \%$ sodium nitrate solution $(0.3 \mathrm{~mL}), 10 \%$ aluminium chloride solution $(0.6 \mathrm{~mL})$ and $1 \mathrm{M}$ sodium hydroxide solution $(2 \mathrm{~mL})$. The mixture was vortex before absorbance was taken at $510 \mathrm{~nm}$ spectrophotometrically. The flavonoid concentration was calculated by using rutin as a standard antioxidant reference with concentration ranging from 0 to $120 \mu \mathrm{g} / \mathrm{mL}$. Samples were analysed in triplicate and expressed as milligram rutin equivalents per litre ( $\mathrm{mg} \mathrm{RE} / \mathrm{L})$. The standard equation curve of rutin was $y=0.007 x+0.002,\left(R^{2}=\right.$ 0.9918).

\subsection{DPPH free radical scavenging assay}

The infusion scavenging activity was determined by measure decolorization of the stable free radical violet colour of DPPH (Lusia et al., 2015). A solution of 0.1 
$\mathrm{mM}$ DDPH in methanol was prepared. Next, infusion and methanolic DPPH free radical reagent was mixed together in ratio of $1: 1$. The reaction mixture was keep in dark at room temperature for 30 mins before absorbance was taken at $517 \mathrm{~nm}$. Blank of deionized water and methanol in ratio of 1:1 was used in the assay. Ascorbic acid with concentration ranging from 1 to $10 \mu \mathrm{g} / \mathrm{mL}$ was used as a reference antioxidant compound. The infusion ability to scavenge the DPPH free radical was calculated as follow:

$$
\text { Inhibition }(\%)=\left[\left(\frac{\text { Acontrol - Asample }}{\text { Acontrol }}\right)\right] X 100 \%
$$

Where $\mathrm{A}_{\text {sample }}=$ Test sample absorbance (DPPH solutions with infusion) and $\mathrm{A}_{\text {control }}=$ Control absorbance (DPPH solution exclude sample)

\subsection{In vitro acetylcholinesterase inhibition assay (AChE)}

Acetylcholinesterase inhibition activity of infusion was determined spectrophotometrically by using Ellman's colorimetric method (Ahmed and Gilani, 2009). $745 \mu \mathrm{L}$ of $50 \mathrm{mM}$ Tris-HCL buffer (pH 8.0), 100 $\mu \mathrm{L}$ of infusion, $15 \mu \mathrm{L}$ of $2 \mathrm{U} / \mathrm{mL}$ acetylcholinesterase enzyme was added and left to incubate for $10 \mathrm{mins}$ at room temperature. Next, $20 \mu \mathrm{L} 10 \mathrm{~mm}$ DTNB in sodium phosphate buffer ( $\mathrm{pH} \quad 8.0$ ) and $20 \quad \mu \mathrm{L} \quad 14 \quad \mathrm{~mm}$ acetylthiocholine iodide (ATCI) was added into the reaction mixture, vortex and incubated at room temperature for another 12 mins. A total of $10 \mu \mathrm{L}$ of 1 $\mathrm{mg} / \mathrm{mL}$ galanthamine was added into the reaction mixture to stop the enzymatic reaction. Absorbance was taken at $412 \mathrm{~nm}$ for every $30 \mathrm{~s}$ for three times with blank of Tris-HCL buffer and sample infusion. Galanthamine hydrobromide, a standard for AChE inhibitor was dissolved in deionized water and used as positive control and percentage of acetylcholinesterase inhibition was calculated by using the following formula:

$$
\text { Inhibition(\%) }=\left[\left(\frac{\text { Acontrol - Asample }}{\text { Acontrol }}\right)\right] \times 100 \%
$$

Where $\mathrm{A}_{\text {sample }}=$ Infusion absorbance and $\mathrm{A}_{\text {control }}=$ Negative control absorbance (enzymatic reaction without sample

\subsection{Statistical analysis}

All assays results were determined in triplicate with three occasions $(n=3)$. Results were expressed as mean \pm standard deviation (S.D). Response surface methodology experimental design was generated and analysed by Design Expert 6.0.4.

\section{Results and discussion}

\subsection{Optimization of MAE parameter}

Central composite experimental design was shown in
Table 1. By using analysis of variance (ANOVA) of the response surface quadratic model, the relationship between the response variable and the independent variable can be identified and explained briefly as shown in Table 2. Significant model of responses variables with insignificant lack of fit TPC (0.2088), TFC (0.2822), DPPH (0.4331), and AChE (0.7920) at $\mathrm{p}>0.05$ indicated that model used is fit with the response variable and able to represent the relationship between responses and independent variables.

The correlation coefficient $\left(\mathrm{R}^{2}\right)$ reveals the total variation present in a model (Hayat et al., 2009). As the correlation coefficients of the responses TPC (0.9718), TFC (0.8793), DPPH (0.8280) and AChE (0.7401) nearly to 1 , these correlation coefficients are acceptable as it explained that $74.01 \%$ to $97.18 \%$ variability of the data can be explained by the model. Apart from that, adequate precision of response variables, TPC (22.329), TFC (10.711), DPPH (8.320) and AChE (6.609) with a ratio greater than 4 is assumed to be desirable and indicated that the model can be used to navigate the signal (Alara et al., 2017).

In optimization coefficient estimation, linear, quadratic and interaction effect of each and between independent variable towards the responses can be examined. A value of $\mathrm{P}<0.05$ indicated that the model terms are significant. Based on Table 2, the total phenolic content was affected most significantly by power (A), followed by Irradiate time (B), quadratic terms power ${ }^{2}\left(\mathrm{~A}^{2}\right)$, brewing ${ }^{2}\left(\mathrm{~B}^{2}\right)$, and interaction between power and irradiate time (AC). Total flavonoid content response was affected by two linear parameters (Power (A) and Irradiate time $(C)$ whereas, single factor of power (A), quadratic factor of brewing time $\left(\mathrm{B}^{2}\right)$ and irradiate time $\left(\mathrm{C}^{2}\right)$, would affect $\mathrm{DPPH}$ response. However, only power (A), and its quadratic relation would affect the effectiveness of AChE response. By neglecting non-significant parameter $(\mathrm{P}>0.1)$, final predictive equation from each actual factors obtained for each responds were as follows:

$$
\begin{aligned}
& Y_{T P C}=252.35+18.92 \mathrm{~A}-3.22 \mathrm{~B}+12.99 \mathrm{C}+ \\
& 10.66 \mathrm{~A}^{2}+5.58 \mathrm{~B}^{2}+1.93 \mathrm{C}^{2}-4.62 \mathrm{AB}+13.87 \\
& \mathrm{AC}-1.54 \mathrm{BC} \\
& Y_{T F C}=101.65+12.42 \mathrm{~A}-2.92 \mathrm{~B}+4.05 \mathrm{C}+1.84 \\
& \mathrm{~A}^{2}-1.0 \mathrm{~B}^{2}+0.78 \mathrm{C}^{2}+0.15 \mathrm{AB}+3.86 \mathrm{AC}-0.38 \\
& \mathrm{BC} \\
& Y_{D P P H}=64.80+2.99 \mathrm{~A}+0.55 \mathrm{~B}-0.78 \mathrm{C}+0.60 \\
& \mathrm{~A}^{2}-1.01 \mathrm{~B}^{2}+0.91 \mathrm{C}^{2}+0.24 \mathrm{AB}-0.02 \mathrm{AC}-0.25 \\
& \mathrm{BC} \\
& \mathrm{Y}_{\mathrm{AChE}}=26.23+2.32 \mathrm{~A}+0.18 \mathrm{~B}+0.55 \mathrm{C}+0.035 \mathrm{~A}^{2}- \\
& 1.37 \mathrm{~B}^{2}-0.51 \mathrm{C}^{2}-0.68 \mathrm{AB}+1.78 \mathrm{AC}+0.54 \mathrm{BC}
\end{aligned}
$$


Table 2. Analysis of variance (ANOVA) response surface quadratic model total phenolic content (TPC), total flavonoid content (TFC), 2,2-diphenyl-1-picryl-hydrazyl free radical scavenging activity (DPPH), acetylcholinesterase inhibition (AChEI).

\begin{tabular}{|c|c|c|c|c|c|c|c|c|}
\hline \multirow[b]{2}{*}{ Response variable } & \multicolumn{2}{|c|}{ TPC (mg GAE/L) } & \multicolumn{2}{|c|}{ TFC (mgRE/L) } & \multicolumn{2}{|c|}{ DPPH (\% Inhibition) } & \multicolumn{2}{|c|}{ AChE (\% Inhibition) } \\
\hline & $\begin{array}{l}\text { Sum of } \\
\text { Squares }\end{array}$ & $\begin{array}{c}\text { p-value } \\
(\text { Prob }>\text { F })\end{array}$ & $\begin{array}{l}\text { Sum of } \\
\text { Squares }\end{array}$ & $\begin{array}{c}\text { p-value } \\
(\text { Prob }>\text { F })\end{array}$ & $\begin{array}{l}\text { Sum of } \\
\text { Squares }\end{array}$ & $\begin{array}{c}\text { p-value } \\
(\text { Prob }>\text { F })\end{array}$ & $\begin{array}{l}\text { Sum of } \\
\text { Squares }\end{array}$ & $\begin{array}{c}\text { p-value } \\
(\text { Prob }>\text { F })\end{array}$ \\
\hline Model & 13490.78 & $<0.0001$ & 3136.88 & 0.0015 & 199.03 & 0.0075 & 175.24 & 0.0435 \\
\hline \multicolumn{9}{|l|}{ Linear terms } \\
\hline $\mathrm{A}$ & 5728.21 & $<0.0001$ & 2469.79 & $<0.0001$ & 143.06 & 0.0002 & 86.22 & 0.0038 \\
\hline $\mathrm{B}$ & 166.4 & 0.0661 & 136.11 & 0.1058 & 4.77 & 0.3078 & 0.5 & 0.7822 \\
\hline $\mathrm{C}$ & 2697.83 & $<0.0001$ & 262.83 & 0.0331 & 9.77 & 0.1551 & 4.77 & 0.3991 \\
\hline \multicolumn{9}{|l|}{ Quadratic terms } \\
\hline $\mathrm{A}^{2}$ & 2858.81 & $<0.0001$ & 85.34 & 0.1895 & 9.16 & 0.1674 & 0.031 & 0.9446 \\
\hline $\mathrm{B}^{2}$ & 783.76 & 0.0012 & 25.07 & 0.463 & 25.85 & 0.0314 & 47.26 & 0.0197 \\
\hline $\mathrm{C}^{2}$ & 93.68 & 0.1527 & 15.36 & 0.5635 & 20.89 & 0.0483 & 6.66 & 0.3225 \\
\hline \multicolumn{9}{|l|}{ Interaction terms } \\
\hline $\mathrm{AB}$ & 171 & 0.063 & 0.18 & 0.9492 & 0.46 & 0.7458 & 3.74 & 0.4537 \\
\hline $\mathrm{AC}$ & 1538.98 & $<0.0001$ & 119.42 & 0.1268 & $3.25 \mathrm{E}-03$ & 0.9782 & 25.45 & 0.0693 \\
\hline $\mathrm{BC}$ & 19 & 0.5017 & 1.15 & 0.8735 & 0.51 & 0.7319 & 2.32 & 0.5528 \\
\hline Lack of fit & 267.41 & 0.2088 & 268.95 & 0.2948 & 18.36 & 0.5941 & 19.43 & 0.792 \\
\hline Adeq precision & 22.329 & & 10.711 & & 8.32 & & 6.609 & \\
\hline $\mathrm{R}^{2}$ & 0.9718 & & 0.8793 & & 0.828 & & 0.7401 & \\
\hline
\end{tabular}

$\mathrm{A}=$ microwave power, $\mathrm{B}=$ brewing time and $\mathrm{C}=$ irradiate time.

Where $\mathrm{A}=$ microwave power; $\mathrm{B}=$ brewing time $(\mathrm{s}) ; \mathrm{C}=$ irradiate time (s).

\subsection{Microwave parameter effects on total phenolic content (TPC)}

Total phenolic content (TPC) was between 239.25 and $338.33 \mathrm{mg}$ gallic acid per litre of infusion. The analysis of data indicated that linear terms of microwave power and irradiate time shows significant effects on the TPC. While interaction term of AC (microwave power and irradiate time) and quadratic terms of $\mathrm{A}^{2}$ and $\mathrm{B}^{2}$ shows significant influenced towards total phenolic content. Equation 4 shows microwave power and irradiate time gave positive effect while brewing time gave negative effects on total phenolic content. All quadratic shows positive effect but only interaction between microwave power and irradiate time shows positive effect towards total phenolic content.

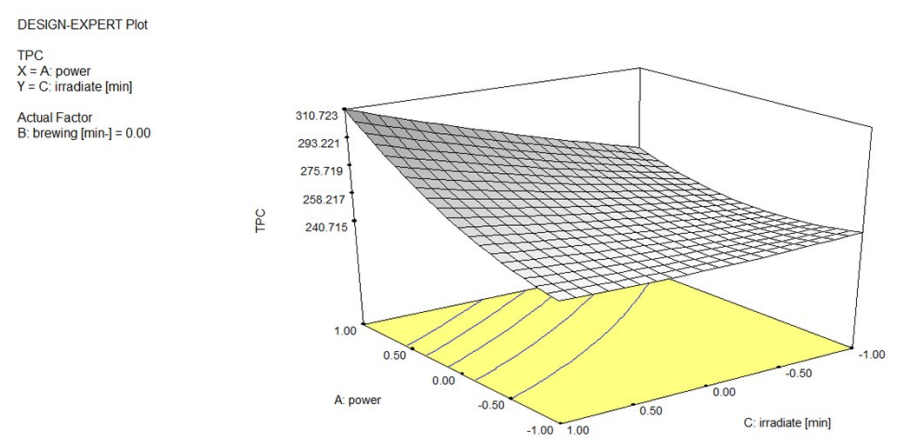

Figure 1. Surface plot effect of microwave power and irradiate time on total phenolic content when brewing time was kept at zero level.
The response surface plot was generated to visualize the effect of the parameters on total phenolic content as shown in Figure 1 to Figure 3. Figure 1 shows the influence of microwave power and irradiates time, Figure 2 shows the influence of microwave power and brewing time while Figure 3 shows brewing time and irradiate time influence on total phenolic content. Higher microwave power with longer extraction time increased the total phenolic content of the infusion.

\subsection{Microwave parameter effect on total flavonoid content}

The total flavonoid content was found in ranged of 81.91 to $133.12 \mathrm{mg}$ rutin per litre of infusion. From the analysis of variance (ANOVA), the linear term of microwave power and irradiate time shows a significant effect on total flavonoid content. However, the interaction and quadratic term between microwave power, brewing time and irradiate time show no

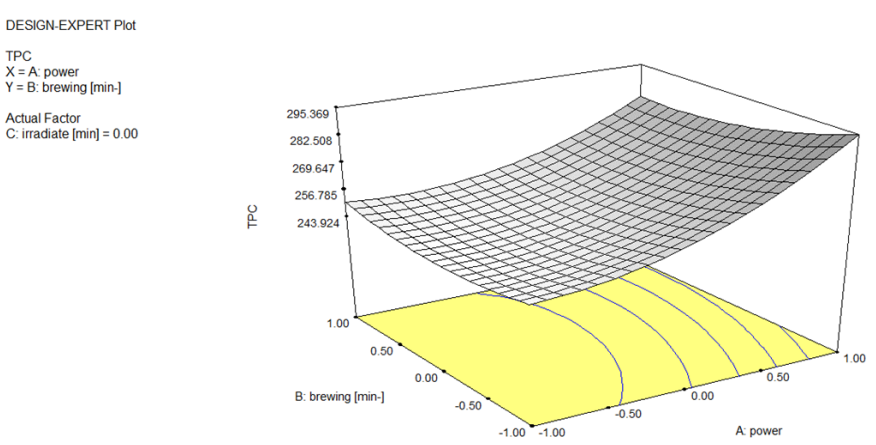

Figure 2. Surface plot effect of microwave power and brewing time on total phenolic content when irradiate time was kept at zero level. 
DESIGN-EXPERT Plot

TPC
$X=B$ : brewni [min-]
$Y=C$ : irradiate [nin]

Actual Factor
A: power $=0.00$

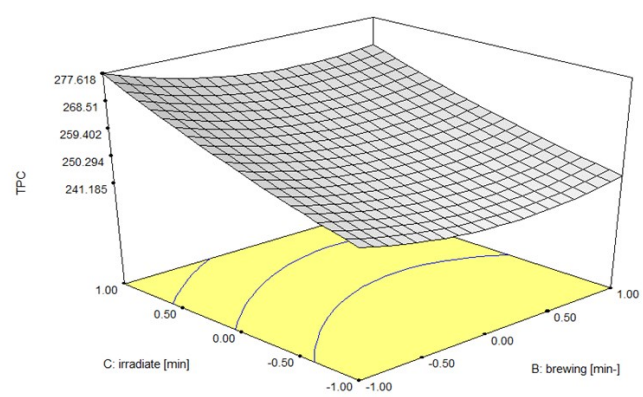

Figure 3. Surface plot effect of irradiate and brewing time on total phenolic content when microwave power was kept at zero level.

DESIGN-EXPERT Plot
TFC
$X=A$. powe
$Y=C$ : irradiate [min]
$\begin{aligned} & \text { Actual Factor } \\ & \text { B. brewing [min }]=0.00\end{aligned}$

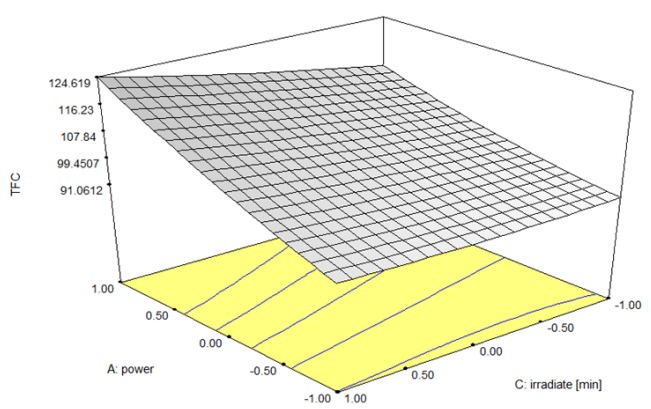

Figure 5. Surface plot effect of microwave power and irradiate time on total flavonoid content when brewing time was kept at zero level.

DESIGN-EXPERT Plot

DPPH
$X=A: p$

Actual Factor

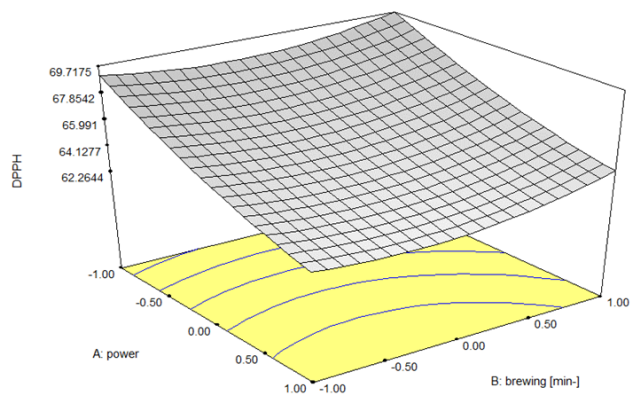

Figure 7. Surface plot effect of microwave power and brewing time on antioxidant DPPH free radical inhibition when irradiate time was kept at zero level.

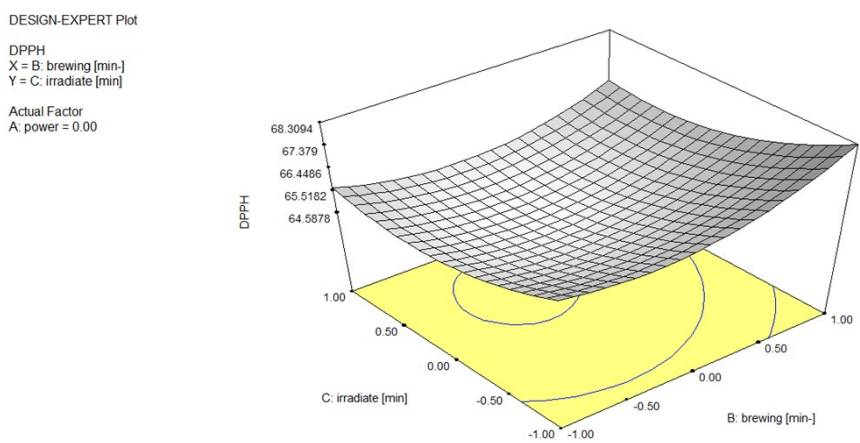

Figure 9. Surface plot effect of irradiate time and brewing time on antioxidant DPPH free radical inhibition when microwave power was kept at zero level.
DESIGN-EXPERT Plot

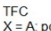

B: brewing [mi

Actual Factor
C. irradiate [min] $=0.00$

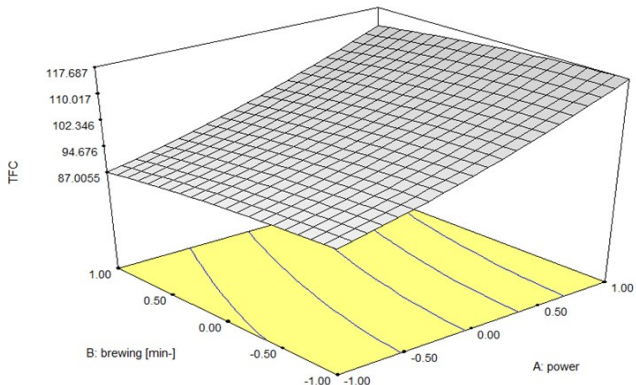

Figure 4. Surface plot effect of brewing time and microwave power on total flavonoid content when irradiate time was kept at zero level.
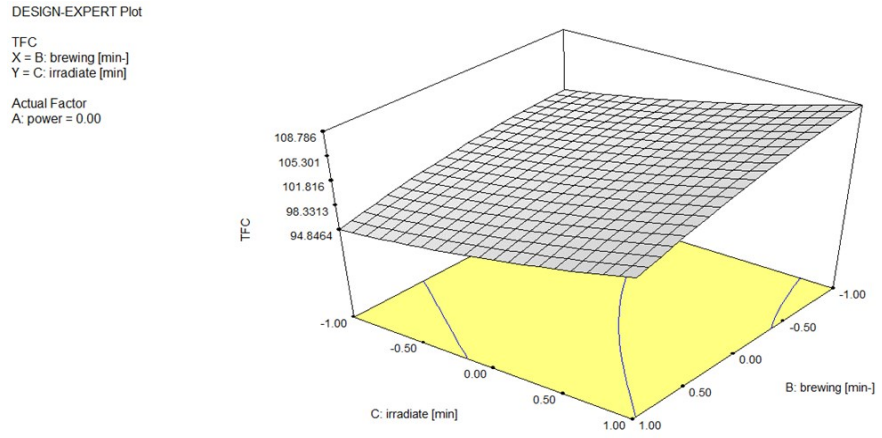

Figure 6. Surface plot effect of brewing time and irradiate time on total flavonoid content when microwave power was kept at zero level.
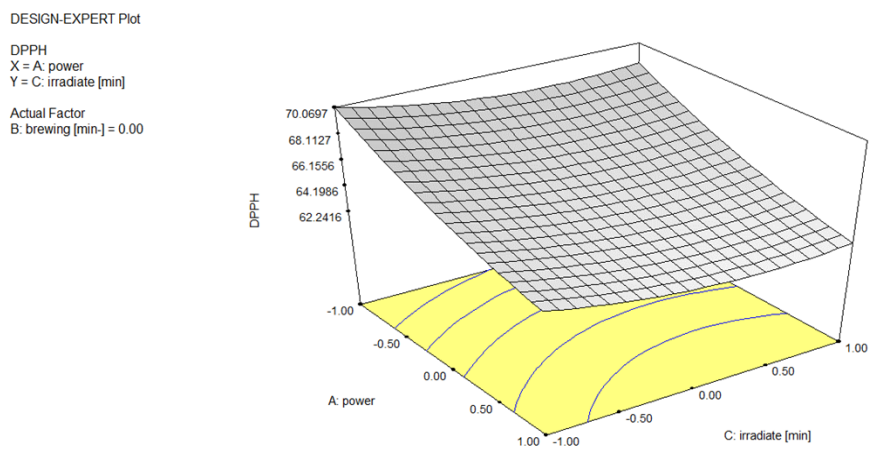

Figure 8. Surface plot effect of microwave power and irradiate time on antioxidant DPPH free radical inhibition when brewing time was kept at zero level.
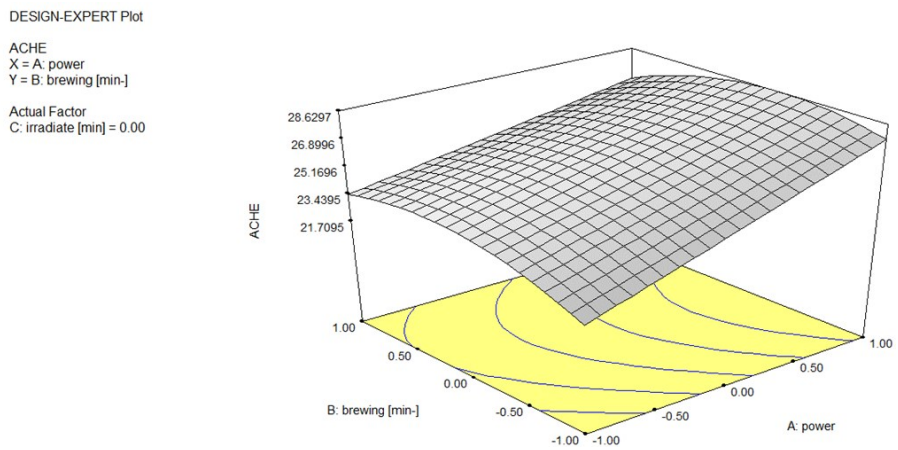

Figure 10. Surface plot effect of microwave power and brewing time on acetylcholinesterase inhibition when irradiate time was kept at zero level. 


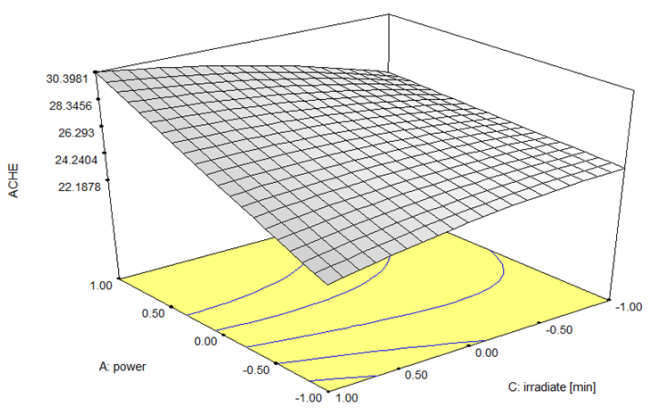

Figure 11. Surface plot effect of microwave power and irradiate time on acetylcholinesterase inhibition when brewing time was kept at zero level.

significant effect on total flavonoid content of the infusion. From equation 5, linear and quadratic of microwave power and irradiate time showed a positive effect on total flavonoid content. Whereas the interaction of microwave power with brewing time $(\mathrm{AB})$ and microwave power and irradiate time (AC) gave a positive effect. While the interaction of brewing time and irradiate time gave negative effect to total flavonoid content. Figures 4 to 6 visualize the effect of the parameters on the total flavonoid content extracted from the $C$. nutans microwave-assisted infusion. In Figure 4 to Figure 6 , the total flavonoid content increased as the parameters of microwave power, brewing time and irradiate time increased.

\subsection{Microwave parameter effect on free radical scavenging $D P P H$}

Antioxidant inhibition of DPPH radical scavenging under different microwave parameter was between 60.64 to $72.84 \%$. Linear term of microwave power gave significant effect while brewing time and irradiate time gave a non-significant effect on antioxidant inhibition activity. The quadratic term of microwave power was not significant to antioxidant inhibition activity. Whereas quadratic term of brewing time and irradiate time gave significant effect to the response activity. However, no significant interaction term was present in the response. Based on equation 6 , the positive effect was found in the linear term of microwave power and brewing time on antioxidant inhibition activity. Whereas quadratic of microwave power and irradiate time along with the interaction between microwave power and brewing time gave a positive effect to the response activity. Response surface was generated and illustrated as shown in Figure 7 to Figure 9. In Figure 7 to Figure 9, the antioxidant DPPH scavenging activity shown an increasing pattern when the microwave power, brewing time and irradiate time increase.

\subsection{Microwave parameter effect on acetylcholinesterase inhibition activity}

The acetylcholinesterase inhibition activity under
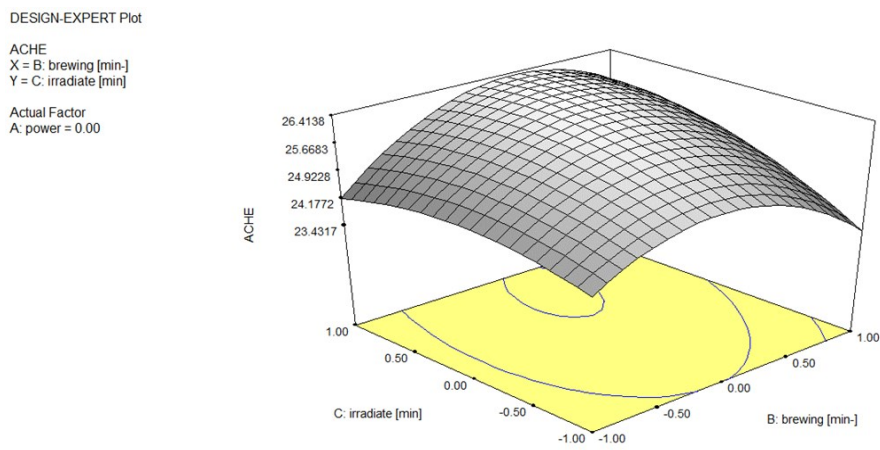

Figure 12. Surface plot effect of brewing time and irradiate time on acetylcholinesterase inhibition when microwave power was kept at zero level.

different microwave parameters was found to be between 18.99 to $31.12 \%$. Linear term of microwave power gave significant effect while linear term of brewing time and irradiate time gave a non-significant effect on response activity. Quadratic term of brewing time gave significant effect while quadratic term of microwave power and irradiate time gave non-significant effect on acetylcholinesterase inhibition activity. Moreover, interaction terms between microwave power with brewing time $(\mathrm{AB})$, microwave power with irradiate time (AC) and brewing time and irradiate time (BC) gave a non-significant effect on acetylcholinesterase inhibition activity. Equation 7 indicated that linear of microwave power, brewing time and irradiate time gave positive effect on acetylcholinesterase inhibition activity. While other positive effect was found only on quadratic of microwave power and interaction between microwave power with irradiate time (AC) and brewing time with irradiate time (BC). The response surface activity of acetylcholinesterase inhibition under the influence of the parameters was illustrated as in Figure 10 to Figure 12. An increasing acetylcholinesterase inhibition pattern was observed in Figures 10 and 11. While in Figure 12, as the irradiate time and brewing time increased, the acetylcholinesterase inhibition activity increased and decreased afterwards.

\subsection{Validation of optimize MAE parameter}

Table 3. Predicted and actual value under optimal condition, (560W, $60 \mathrm{~s}$ brewing time, $240 \mathrm{~s}$ irradiate time).

\begin{tabular}{|c|c|c|c|c|}
\hline Responses & 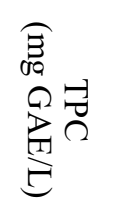 & 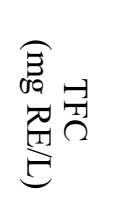 & 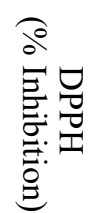 & 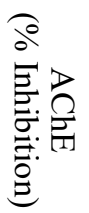 \\
\hline Predicted value & 252.35 & 101.65 & 64.8 & 26.22 \\
\hline Actual value & 251.58 & 102.21 & 62.23 & 24.77 \\
\hline
\end{tabular}

The optimal condition that was obtained by using the mathematical model were as follow: microwave power $(560 \mathrm{~W})$; brewing time $(60 \mathrm{~s})$ and irradiate time $(240 \mathrm{~s})$. Thus, optimal verification was performed. Under this optimal condition, the predicted value and actual value 
of each response were shown in Table 3. As the actual values were closed to predictive value, indicating that the model was reliable.

\section{Conclusion}

From this study, the influence of MAE variables towards response phytochemical activities (TPC, TFC), antioxidant activities (DPPH) and enzymatic activity AChE of $C$. nutans tea infusions was studied using central composite design (CCD) of response surface methodology (RSM). The findings show that brewing time, microwave power and irradiate time significantly affected the responses, With the optimal condition of 560 $\mathrm{W}, 60 \mathrm{~s}$ brewing time and $240 \mathrm{~s}$ irradiate time, the experimental data is in agreement with the predicted data of the mathematical model (TPC $251.58 \mathrm{mg}$ GAE/L; TFC $102.21 \mathrm{mg} \mathrm{RE} / \mathrm{L} ; 62.23 \%$ DPPH inhibition; $24.77 \%$ AChE inhibition). In general, this study suggested this model can be used to enhance extractions of phytochemical, antioxidant and acetylcholinesterase inhibition properties.

\section{Conflict of interest}

The authors have no conflict of interest.

\section{Acknowledgments}

Financial support from research fund MDR H506 and E15501 provided by Research Management Centre, Universiti Tun Hussein Onn Malaysia is gratefully acknowledged.

\section{References}

Abdullah, S., Shaari, A.R. and Azimi, A. (2012). Effect of drying methods on metabolites composition of Misai kucing (Orthosiphon stamineus) leaves. APCBEE Procedia, 2, 178-182. https:// doi.org/10.1016/j.apcbee.2012.06.032

Ahmed, T. and Gilani, A.H. (2009). Inhibitory effect of curcuminoids on acetylcholinesterase activity and attenuation of scopolamine-induced amnesia may explain medicinal use of turmeric in Alzheimer's disease. Pharmacology, Biochemistry and Behavior, 91(4), 554-559. https://doi.org/10.1016/ j.pbb.2008.09.010

Alara, O.R., Abdurahman, N.H. and Olalere, O.A. (2017). Optimization of microwave-assisted extraction of flavonoids and antioxidants from Vernonia amygdalina leaf using response surface methodology. Food and Bioproducts Processing, 107, 36-48. https://doi.org/10.1016/ j.fbp.2017.10.007
Caleja, C., Barros, L., Prieto, M.A., Barreiro, M.F., Oliveira, M.B.P.P. and Ferreira, I.C.F.R. (2017). Extraction of rosmarinic acid from Melissa officinalis L. by heat-, microwave- and ultrasoundassisted extraction techniques: A comparative study through response surface analysis. Separation and Purification Technology, 186, 297-308. https:// doi.org/10.1016/j.seppur.2017.06.029

Dai, J. and Mumper, R.J. (2010). Plant phenolics: Extraction, analysis and their antioxidant and anticancer properties. Molecules, 15(10), 73137352. https://doi.org/10.3390/molecules15107313

Grisaru, D., Sternfeld, M., Eldor, A., Glick, D. and Soreq, H. (1999). Structural roles of acetylcholinesterase variants in biology and pathology. European Journal of Biochemistry, 264 (3), 672-686. https://doi.org/10.1046/j.14321327.1999.00693.x

Hayat, K., Hussain, S., Abbas, S., Farooq, U., Ding, B., Xia, S. and Xia, W. (2009). Optimized microwaveassisted extraction of phenolic acids from citrus mandarin peels and evaluation of antioxidant activity in vitro. Separation and Purification Technology, 70 (1), $\quad$ 63-70. https://doi.org/10.1016/ j.seppur.2009.08.012

Kongkaew, C. and Chaiyakunapruk, N. (2011). Efficacy of Clinacanthus nutans extracts in patients with herpes infection: Systematic review and metaanalysis of randomised clinical trials. Complementary Therapies in Medicine, 19(1), 4753. https://doi.org/10.1016/j.ctim.2010.12.003

Kormin, F., Ahmed, I., Yunus, R.M. and Yusof, Z.A.M. (2010). The potential of modified microwave extraction system (mmes) to extract bioactive components from ferns. International Journal of Engineering and Technology, 10(2), 7-21.

Kormin, F., Khan, M., Shafie, N.S.M., Nour, A.H. and Yunus, R.M. (2018). Statistical mixture design: study of solvent performance in temperature controlled microwave assisted extraction system on antioxidant properties of Nephrolepis biserrata (Schott.) Sw. frond extract. International Journal of Engineering and Technology, 7, 605-609.

Krishnan, R.Y. and Rajan, K.S. (2016). Microwave assisted extraction of flavonoids from Terminalia bellerica: Study of kinetics and thermodynamics. Separation and Purification Technology, 157, 169178. https://doi.org/10.1016/j.seppur.2015.11.035

Lau, K.W., Lee, S.K. and Chin, J.H. (2014). Effect of the methanol leaves extract of Clinacanthus nutans on the activity of acetylcholinesterase in male mice. Journal of Acute Disease, 3(1) 22-25. https:// doi.org/10.1016/S2221-6189(14)60005-6 
Le, C.F., Kailaivasan, T.H., Chow, S.C., Abdullah, Z., Ling, S.K. and Fang, C.M. (2017). Phytosterols isolated from Clinacanthus nutans induce immunosuppressive activity in murine cells. International Immunopharmacology, 44, 203-210. https://doi.org/10.1016/j.intimp.2017.01.013

Lusia, B.M., Hasmadi, M., Zaleha, A.Z. and Fadzelly, M.A.B. (2015). Effect of different drying methods on phytochemicals and antioxidant properties of unfermented and fermented teas from Sabah snake grass (Clinacanthus nutans Lind.) leaves. International Food Research Journal, 22(2), 661670.

Maisarah, A.M., Amira, N.B., Asmah, R. and Fauziah, O. (2013). Antioxidant analysis of different parts of Carica papaya. International Food Research Journal, 20(3), 1043-1048.

Mustapa, A.N., Martin, A., Gallego, J.R., Mato, R.B. and Cocero, M.J. (2015). Microwave-assisted extraction of polyphenols from Clinacanthus nutans Lindau medicinal plant: Energy perspective and kinetics modeling. Chemical Engineering and Processing: Process Intensification, 97, 66-74. https:// doi.org/10.1016/j.cep.2015.08.013

Mustapa, A.N., Martin, Á., Mato, R.B. and Cocero, M.J. (2015). Extraction of phytocompounds from the medicinal plant Clinacanthus nutans Lindau by microwave-assisted extraction and supercritical carbon dioxide extraction. Industrial Crops and Products, 74, 83-94. https://doi.org/10.1016/ j.indcrop.2015.04.035

Neagu, E., Paun, G., Albu, C. and Radu, G.L. (2015). Assessment of acetylcholinesterase and tyrosinase inhibitory and antioxidant activity of Alchemilla vulgaris and Filipendula ulmaria extracts. Journal of the Taiwan Institute of Chemical Engineers, 52, 1-6. https://doi.org/10.1016/j.jtice.2015.01.026

Ng, P.Y., Chye, S.M., Ng, C.H., Koh, R.Y., Tiong, Y.L., Pui, L.P. and Ng, K.Y. (2017). Clinacanthus nutans hexane extracts induce apoptosis through a caspasedependent pathway in human cancer cell lines. Asian Pacific Journal of Cancer Prevention, 18(4), 917926.

Ouattara, N., Meda, R.N.T., Hilou, A., Guenne, S., Konate, K., Coulibaly, A.Y. and Nacoulma, O.G. (2013). Anti-acetylcholinesterase and antioxidant activities and HPLC- MS analysis of polyphenol from extracts of Nelsonia canescens (Lam.) Spreng. Asian Pacific Journal of Tropical Disease, 3(5), 382 -388. https://doi.org/10.1016/S2222-1808(13)600882

Panja, P. (2018). Green extraction methods of food polyphenols from vegetable materials. Current
Opinion in Food Science, 23, 173-182. https:// doi.org/10.1016/j.cofs.2017.11.012

Rahim, M.H.A., Zakaria, Z.A., Sani, M.H.S., Omar, M.H., Yakob, Y., Cheema, M.S. and Kadir, A.A. (2016). Methanolic extract of Clinacanthus nutans exerts antinociceptive activity via the opioid/ nitric oxide-mediated, but cGMP-independent, pathways. Evidence-Based Complementary and Alternative Medicine, 2016, 1494981. https:// doi.org/10.1155/2016/1494981

Sakdarat, S., Shuyprom, A., Pientong, C., Ekalaksananan, T. and Thongchai, S. (2009). Bioactive constituents from the leaves of Clinacanthus nutans Lindau. Bioorganic and Medicinal Chemistry, 17(5), 1857-1860. https:// doi.org/10.1016/j.bmc.2009.01.059

Siew, Y.Y., Zareisedehizadeh, S., Seetoh, W.G., Neo, S.Y., Tan, C.H. and Koh, H.L. (2014). Ethnobotanical survey of usage of fresh medicinal plants in Singapore. Journal of Ethnopharmacology, 155(3), 1450-1466. https://doi.org/10.1016/ j.jep.2014.07.024

Simic, V.M., Rajkovic, K.M., Stojicevic, S.S., Velickovic, D.T., Nikolic, N.C., Lazic, M.L. and Karabegovic, I.T. (2016). Optimization of microwave-assisted extraction of total polyphenolic compounds from chokeberries by response surface methodology and artificial neural network. Separation and Purification Technology, 160, 8997. https://doi.org/10.1016/j.seppur.2016.01.019

Veggi, P.C., Martinez, J. and Meireles, M.A.A. (2013). Fundamentals of Microwave Extraction. In Chemat, F. and Cravotto, G. (Eds). Microwave-assisted extraction for bioactive compounds: Theory and practice, p. 15-32. New York: Springer. https:// doi.org/10.1007/978-1-4614-4830-3 2

Vuong, Q.V., Tan, S.P., Stathopoulos, C.E. and Roach, P.D. (2012). Improved extraction of green tea components from teabags using the microwave oven. Journal of Food Composition and Analysis, 27(1), 95-101. https://doi.org/10.1016/j.jfca.2012.06.001

Yahaya, R., Dash, G.K., Abdullah, M.S. and Mathews, A. (2015). Clinacanthus nutans (burm. F.) Lindau: an useful medicinal plant of south-east Asia. International Journal of Pharmacognosy and Phytochemical Research, 7(6), 1244-1250. 